\title{
Soroprevalência de brucelose em suínos de granjas comerciais e em criatórios de subsistência*
}

\section{Seroprevalence of brucellosis in farm animals and in subsistence breeders}

\author{
Paulo Henrique Braz, ${ }^{* *}$ Raquel Soares Juliano, ${ }^{* * *}$ Reny Correa Lyrio, ${ }^{* * *}$ Rita de Cássia da Silva Paes, ${ }^{* \star * *}$ \\ Jamil Manoel Leal Filho, ${ }^{* * * *}$ Aiesca Oliveira Pellegrin ${ }^{* * *}$
}

\begin{abstract}
Resumo
A suinocultura industrial compreende o conjunto de produtores que incorporam os avanços tecnológicos em genética, nutrição, sanidade e demais aspectos produtivos, enquanto a suinocultura de subsistência desempenha um papel importante para a alimentação humana, sendo a criação de suínos em criatórios amplamente difundida entre os pequenos proprietários de terra ou em assentamentos. Este trabalho teve como objetivo avaliar a pesquisa de anticorpos contra Brucella sp. nos suínos de granjas comerciais, criatórios de subsistência e javalis asselvajados. Foram visitados 32 criatórios de suínos domésticos localizados na região sul de Mato Grosso do Sul. Considerando-se os fenótipos, verificou-se que os sinais indicativos de contato têm influência do município onde está situada a propriedade $\left(x^{2}=8.8594, p=0,0029\right)$, sendo que o município de Deodápolis tem uma chance de ocorrência mais elevada (OR=13,00;IC95\%:2,12-79,59). Através da detecção fenotípica observa-se a presença de animais híbridos nas propriedades analisadas, e evidencia-se assim que os animais da propriedade em algum momento entraram em contato com suínos asselvajados, os quais podem ser responsáveis pela disseminação de diversas patologias. A ausência da detecção de anticorpos anti-Brucella sp. em suínos de criatórios sugere que a bactéria não é circulante nas populações de javalis nas áreas de estudo.
\end{abstract}

Palavras chave: Criatórios para subsistência, suídeos, saúde única, zoonoses.

\begin{abstract}
Industrial pig farming comprises the group of producers that incorporate technological advances in genetics, nutrition, health and other productive aspects, while subsistence pig farming plays an important role for human nutrition, with the creation of pigs in farms being widely spread among small farms. landowners or settlements. This study aimed to evaluate the search for antibodies against Brucella sp. pigs on commercial farms, livestock farms and wild boars. Were visited 32 domestic swine farms located in the southern region of Mato Grosso do Sul. Considering the phenotypes, it was found that the indicative signs of contact have influence from the municipality where the property is located $(x 2=8.8594, p=0.0029)$, and the municipality of Deodápolis has a higher chance of occurrence (OR=13,00;IC95\%:2,12-79,59). Through the phenotypic detection, the presence of hybrid animals in the analyzed properties is clearly observed, and it is evident that the animals of the property at some point came into contact with pigs, which may be responsible for the spread of several pathogens. The absence of detection of anti-Brucella sp. in breeding pigs it suggests that the bacteria is not circulating in wild boar populations in the study areas.
\end{abstract}

Keywords: Livelihoods, participatory methodology, one health, zoonoses.

\section{Introdução}

No Brasil, existem diferentes formas de exploração da suinocultura, baseada na utilização de tecnologias pelo produtor. A suinocultura industrial compreende o conjunto de produtores que incorporam os avanços tecnológicos em genética, nutrição, sanidade e demais aspectos produtivos, enquanto a suinocultura de subsistência representa o conjunto de produtores para os quais a produção é destinada ao consumo próprio ou utiliza canais de processamento e distribuição informais (MIELE \& MACHADO, 2005)
O sistema de criação de subsistência desempenha um papel importante para a alimentação humana, garantindo uma fonte de renda, fonte de proteína animal e acesso alimentar às famílias que vivem em áreas rurais. Por outro lado, nestes criatórios, não há implementação de boas práticas de gestão, não sendo previstas na legislação normas de biosseguridade (FAO, 2012).

Os suínos domésticos e os javalis pertencem à mesma espécie (Sus scrofa), podendo ser reservatórios de agentes de diversas doenças de potencial zoonótico. O risco ocorre tanto às criações comerciais ou criatórios de subsistência, quando o contato

\footnotetext{
*Recebido em 28 de maio de 2021 e aceito em 1 de julho de 2021.

${ }^{* *}$ Docente do Instituto Federal Farroupilha, campus Frederico Westphalen, RS, Brasil. E-mail: paulo.braz@iffarroupilha.edu.br.

***Pesquisadora da Empresa Brasileira de Pesquisa Agropecuária (EMBRAPA-Pantanal), Corumbá, MS, Brasil.

****Agência Estadual de Defesa Sanitária Animal e Vegetal do Mato Grosso do Sul (IAGRO), Campo Grande, MS, Brasil.

*****Ministério da Agricultura, Pecuária e Abastecimento (MAPA), Campo Grande, MS, Brasil.
} 
entre ambas as populações não pode ser evitado, com para a população que pode consumir uma carne contaminada (ALBINA et al., 2000).

O monitoramento sorológico entre as populações de espécies domésticas e asselvajadas torna-se uma importante ferramenta para demostrar o contato entre as espécies (BRAZ et al., 2019). Além disso, patógenos transmitidos de forma venérea, como a Brucella sp., são adequados como indicadores biológicos de contato, por se tratar de bactéria transmitida entre o contato direto entre animais no momento do coito (OIE, 2012).

A Brucella suis é considerada endêmica em algumas populações de suínos selvagens na América do Norte e em javalis na Europa (GARIN-BASTUJI et al., 2000; BEJA-PEREIRA et al., 2009). Até o presente momento, pouco se conhece sobre a epidemiologia das doenças em suínos asselvajados no estado de Mato Grosso do Sul.

Este trabalho teve por objetivo avaliar a soroprevalência de brucelose, através da pesquisa de anticorpos contra Brucella sp. nos suínos de granjas comerciais e criatórios de subsistência que contenham em seu rebanho suínos híbridos, decorrente do cruzamento entre suínos domésticos e javalis asselvajados.

\section{Material e Métodos}

O experimento foi aprovado pela Comissão de Ética no Uso de Animais da Universidade Federal de Mato Grosso do Sul (UFMS), sob protocolo número 705/2015.

Os 115 criatórios comerciais de suínos foram selecionados ao acaso, localizados no sul de Mato Grosso do Sul, nos municípios Dourados, Itaporã, Maracaju, Ponta Porã, Rio Brilhante, São Gabriel D'Oeste e Coxim. Dentre os criatórios visitados, coletouse 22 amostras de soro em Dourados, 14 em Itaporã, 13 em Maracaju, 64 em Ponta Porã, 58 em Rio Brilhante, 197 em São Gabriel D'Oeste e 1 em Coxim, totalizando 369 amostras de soro analisadas dos criatórios comerciais de suínos. As amostras de soro foram fornecidas pela Agência Estadual de Vigilância Sanitária Animal e Vegetal.

Foram visitados 32 criatórios de suínos domésticos, localizados no sul de Mato Grosso do Sul, nos municípios de Angélica, Deodápolis, Nova Alvorada do Sul e Rio Brilhante. Dentre os criatórios visitados, 16 encontravam-se em Deodápolis, 4 em Angélica, 9 em Rio Brilhante e 3 em Nova Alvorada do Sul. Esta localização foi escolhida por se tratar de uma região cuja presença de javalis e seus híbridos já havia sido registrada anteriormente (PEDROSA et al., 2015).

Com a finalidade da avaliação de indicadores fenotípicos, foram registradas imagens dos suínos dos criatórios para análise das características fenotípicas dos animais. Foram considerados cruzados os animais com aumento do comprimento do focinho e/ou presença de listras no dorso do animal.

Dentre os 32 criatórios visitados, foram coletadas 38 amostras dos leitões híbridos com características fenotípicas evidentes para o cruzamento entre espécies. e utilizados os testes de triagem do antígeno acidificado tamponado (AAT) indicado em BRASIL (2006), a fim de verificar a possível transmissão da bactéria entre animais asselvajados e domésticos. Além disso, foi realizado o teste de polarização fluorescente (FPA), como descrito no manual do kit de diagnóstico (BRUCELLA FPA®,
Estados Unidos), na diluição de 1:50. As amostras com resultado de 20 unidades de milipolarização $(\mathrm{mP})$ superior à média do controle negativo foram consideradas positivas.

Os dados foram tabulados e as variáveis de risco analisadas por meio da estimativa pontual e intervalar da odds ratio (OR), com intervalo de confiança de $95 \%$. O teste de hipóteses foi realizado com o teste de qui-quadrado ou teste exato de Fisher, quando indicado (SAMPAIO, 2007).

\section{Resultados}

Para se caracterizar uma suinocultura de subsistência, foi quantificado o número total de animais por propriedade, obtendose o total entre 1 e 40 animais, com uma média de 11 animais por propriedade rural. Como nestas propriedades não há controle e manejo de parto, torna-se restrito o número de porcas recém paridas, além deste tipo de criação se caracterizar por pequenos números de animais.

Quando associados os fenótipos "focinhos longos" e "presença de leitões com pelagem com listras" de forma associada, observou-se que no município de Deodápolis 13 (40,6\%) ) propriedades (Figura 1) apresentavam animais com esses sinais, enquanto que em Rio Brilhante e Nova Alvorada do Sul esses sinais estavam presentes em apenas $3(9,3 \%)$ propriedades. Com exceção do município de Angélica, constatou-se que os sinais indicativos de contato têm influência do município onde está situada a propriedade $\left(x^{2}=8.8594, p=0,0029\right)$, sendo que o município de Deodápolis tem maior chance de ocorrência (OR=13,00; IC95\%:2,12-79,59) de contato entre as espécies. O nascimento de leitões listrados sugere a introdução e contato com um animal de fenótipo puro indicando claramente uma invasão relativamente recente do javali europeu na região (SALVADOR \& FERNANDEZ, 2014).

Figura 1: Presença de listras dorsais e longitudinais em leitões, caracterizando o cruzamento entre suínos domésticos e javalis asselvajados. Observa-se na seta um leitão com listra dorsal e focinho comprido.

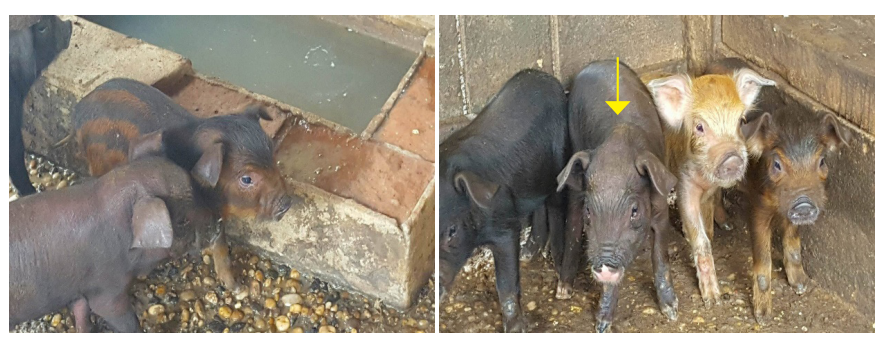

No município de Rio Brilhante, cinco das 9 propriedades possuíam instalações de alvenaria e em somente uma delas foi registrada a presença de uma única fêmea adulta, de pelagem preta, com discreto aumento do focinho, porém, sem a presença da leitegada não foi possível associar a ocorrência do indicador de pelagem dos leitões, o que tornaria confirmatória a ocorrência de cruzamento com javali europeu. No município de Angélica não foram encontrados animais om tais características.

Já, no município de Deodápolis, 13 das 16 propriedades foram registradas a presença de animais com alterações fenotípicas, como animais de focinho longo (8/16) e leitões com listras e focinho longo (5/16). Em Nova Alvorada do Sul, emduas propriedades haviam leitões híbridos, com listras em sua pelagem. 
Um total de 38 leitões com fenotípicos híbridos foram selecionados para coleta de amostras de sangue para investigação de Brucela suis. Por ambas as técnicas de AAT e polarização por fluorescência, obteve-se resultado negativo em todas as amostras. Porém, a detecção de vários criatórios com presença de suínos híbridos claramente detectados por evidências fenotípicas sugere que os javalis da região não tiveram contato com os criatórios infectados por Brucella sp.

\section{Discussão}

As características fenotípicas observadas do cruzamento entre suínos domésticos e javalis são bastante perceptíveis, já que os animais apresentam uma aparência robusta com membros fortes e focinhos longos desenvolvidos por uma placa de cartilagem para auxiliar na procura de raízes e alimentos, além de pelagem ruiva e listras longitudinais pelo corpo de animais jovens (MAPSTON, 2012; IBAMA, 2016). Tais características foram utilizadas para o reconhecimento do processo de hibridação entre os suínos domésticos e javalis asselvajados encontrados nas propriedades visitadas, sendo considerados bons indicadores de contato.

Um estudo realizado por Salvador \& Fernandez (2014), nas florestas de araucária do estado de Santa Catarina, utilizaram o indicador fenotípico para documentar o processo de invasão pelo javali europeu, registrando que $91 \%$ dos leitões fotografados em armadilhas apresentaram os padrões de pelagem típica do fenótipo de animais juvenis do javali europeu.

Uma das maiores preocupações com relação ao contato entre as espécies domésticas e asselvajadas é a reintrodução de doenças consideradas erradicadas em suínos domésticos (WITMER et al., 2003; CORN et al., 2005). A precariedade de bioseguridade favorece a entrada de doenças transmissíveis com potencial disseminação, que pode ocorrer principalmente por contato direto entre os animais (CHRISTENSEN et al., 1993). As operações pouco tecnificadas são consideradas os pontos cruciais para a introdução de doenças, ressaltando-se que a transmissão de doenças de suínos asselvajados para suínos domésticos podem ser grandes transmissores de doenças para animais domésticos, tais como a Brucella suis (SEWARD et al., 2004; CORN et al., 2009; WYCKOFF et al., 2009).

Estudos publicados anteriormente por Braga et al. (2013), sugere uma prevalência de $0,52 \%$ de anticorpos anti-Brucella spp. em suínos de criações intensivas e extensivas do estado do Piauí, revelando uma grande preocupação com a possibilidade de disseminação da circulação bacteriana, e a própria contaminação da população que tem contato com estes animais.

A erradicação da brucelose em países como os Estados Unidos da América, por exemplo, é ameaçada por esta doença ser compartilhada entre populações de suínos selvagens. Existe a possibilidade dos javalis asselvajados se contaminarem com os suínos domésticos mantidos em criatórios, visto que foi observado que estes animais são criados em condições sanitárias precárias, havendo desta forma uma abordagem de risco para ambas populações de suínos (WYCKOFF et al., 2009).

Para comprovar tal contato entre os javalis asselvajados e suínos domésticos, Corn et al. (2009), utilizaram a evidências sorológica de Brucella abortus pelo teste de AAT. Dentre 170 animais testados, apenas em $14 \%$ dos casos foram sorologicamente positivos para a doença. A sensibilidade de ensaios sorológicos para brucelose em um estudo com javalis foi considerada baixa (14\% de 170 animais) (CORN et al., 2009) considerando o isolamento do agente como padrão-ouro, podendo refletir a cronicidade da infecção nessas populações (STOFFREGEN et al., 2007).

A associação entre a utilização de cães para afugentar os javalis asselvajados juntamente com construções com melhor biosseguridade aparente, como os criatórios construídos em alvenaria, demonstraram aumentar a eficácia para evitar o contato entre os suínos asselvajados e domésticos. Criações extensivas em regiões onde existe a presença de javali asselvajado apresentam um risco $63 \%$ maior de contato pela presença de porcas no cio, devido a nenhuma barreira que impeça o contato (WYCKOFF et al., 2009; WU et al., 2012).

Considerando a importância da suinocultura comercial na região Sul do estado do Mato Grosso do Sul, o potencial risco de aumento da população de híbridos deve ser objeto de ações de monitoramento constante para que sua gestão seja empreendida com base em dados técnicos (BRAZ et al., 2019).

A transmissão de zoonoses têm sido motivo de preocupação para autoridades sanitárias nos países onde existe a caça e/ ou consumo de carne exótica. Nos Estados Unidos a brucelose humana por Brucella suis é considerada de notificação obrigatória, sendo que o número de casos notificados tem sido nos maiores nos estados da Califórnia, Texas e Flórida, com os registros da doença comumente associados ao risco ocupacional da caça, permitida em quase todos os estados onde os suídeos asselvajados estão presentes (CDC, 2009).

Muitos avanços ocorreram na suinocultura comercial nas últimas décadas. Houve aprimoramento gerencial, melhorias nos sistemas de manejo, instalações e sanidade, com políticas públicas implementadas pelo Programa Nacional de Sanidade Suídea - PNSS (BRASIL, 2004). A suinocultura de subsistência ainda permanece, no entanto, operando por meio de modelos rústicos, com precariedade na assistência técnica e de manejo (SILVA FILHA et al., 2008; ROCHA et al., 2016).

Os criadores não registram índices sanitários e/ou zootécnicos, importantes para o controle do rebanho, tais como número de partos, idade a desmama e, sobretudo, dados que permitam inferir sobre a taxa de mortalidade de leitões, não estando também previstas pelos programas oficiais, medidas de bioseguridade para essa categoria de propriedades (ROCHA et al., 2016).

A suinocultura para a subsistência tem organização de base familiar, o que influencia toda a cadeia suinícola, envolvendo variáveis sociais, econômicas, legais, sanitárias e ambientais (RACHED, 2009). Dentre as maiores preocupações podemos evidenciar a recorrência de questões acerca da sanidade dos rebanhos e a segurança do produto. Nesse sentido, políticas públicas que promovam a inclusão desses pequenos produtores, com implementação de ações de educação sanitária e assistência técnica devem ser objeto constante da atenção oficial.

\section{Conclusão}

Através da detecção fenotípica observa-se claramente a presença de animais híbridos nas propriedades analisadas, e evidencia-se assim que os animais da propriedade em algum 
momento entraram em contato com suínos asselvajados, os quais podem ser responsáveis pela disseminação de diversas patologias. A ausência da detecção de anticorpos anti-Brucella sp. em suínos de criatórios sugere que a bactéria não é circulante nas populações de javalis nas áreas de estudo, dificultando a ocorrência de brucelose.

\section{Agradecimentos}

À Fundação de Apoio ao Desenvolvimento do Ensino, Ciência e Tecnologia do Estado de Mato Grosso do Sul pelo apoio ao projeto e concessão da bolsa pela Chamada FUNDECT N 08/2015. Ao Dr. Flábio Ribeiro de Araújo, pesquisador da Embrapa Gado de Corte, pelo apoio nas análises de Polarização por Fluorescência.

\section{Referências}

ALBINA, E.; MESPLÈdE, A.; CHENUT, G.; LE POTIER, M. F.; BOURBAO, G.; LE GAL, S.; LEFORBAN, Y. Serological survey on classical swine fever (CSF), Aujeszkys disease (AD) and porcine reproductive and respiratory syndrome (PPRS) virus infections in French wild boars from 1991 to 1998 . Veterinary Microbiology, v.77, p.43-57, 2000.

BEJA-PEREIRA, A.; BRICKER, B.; CHEN, S.; ALMENDRA, C.; WHITE, P.J.; LUIKART, G. DNA genotyping suggests that recent brucellosis outbreaks in the Greater Yellowstone área originated from elk. Journal wildlife diseases, v.45, p.1174-1177, 2009.

BRAGA, J. F. V.; TEIXEIRA, M. P. F.; FRANKLIN, F. L. A. A.; SOUZA, J. A. T.; SILVA, S. M. M. S.; GUEDES, R. M. C. Soroprevalência de pseudorraiva, peste suína clássica e brucelose em suínos do estado do Piauí. Arquivo Brasileiro de Medicina Veterinária e Zootecnia, v.65, n.5, p.1321-1328, 2013.

BRASIL, Ministério da Agricultura, Pecuária e Abastecimento. Secretaria de Defesa Agropecuária - Departamento de Saúde Animal, 2006. Programa Nacional de Controle e Erradicação da Brucelose e Tuberculose (PNCEBT) - Manual Técnico. Brasília: MAPA / DAS / DSA, 188p., 2006.

BRASIL. Ministério da Agricultura, Pecuária e Abastecimento. Instrução Normativa $n^{\circ} 47$, de 18 de junho de 2004. Diário Oficial [da] República Federativa do Brasil, Brasília, DF, 23 jun. 2004. Disponível em: <http://sistemasweb.agricultura.gov.br/sislegis/ action/detalhaAto.do?method=consult arLegislacaoFederal $>$. Acesso em: 27 maio 2014.

BRAZ, P. H.; OLIVEIRA, M. R. ; SILVA, V. S. ; TOMAS, W. M.; JULIANO, R. S. ; MOREIRA, T. A. ; ZIMMERMMANN, N. P. ; PELLEGRIN, A. O. . Risk of exposure of farms and subsistence nurseries to contact with wild boar in southern Mato Grosso do Sul. Pesquisa veterinária brasileira, v. 39, p. 148-154, 2019.

CDC - Center For Diseases Control And Prevention. Brucella suis Infection Associated with Feral Swine Hunting --- Three States, 2007-2008. Morbidity and Mortality Weekly Report (MMWR), v.58, n.22, p.618-621, 2009. Disponível em: <http://www.cdc.gov/ $\mathrm{mmwr} / \mathrm{preview} / \mathrm{mmwrhtml} / \mathrm{mm} 5822 \mathrm{a} 3 . \mathrm{htm}>$. Acesso 21 outubro 2016.

CHRISTENSEN, L. S.; MORTENSEN, S.; BOTNER, A.; STRANDBYGAARD, B.S.; RONSHOLD, L.; HENRIKSEN, C.A.; ANDERSEN, J.B. Further evidence of long distance airborne transmission of Aujeszky's disease (pseudorabies) virus. Veterinary Record, v.132, p.317-321, 1993.

CORN, J. L.; CUMBEE, J. C.; BARFOOT, R.; ERICKSON, G. A. Pathogen exposure in feral swine populations geographically associated with high densities of transitional swine premises and commercial swine production. Journal of Wildlife Diseases, v.45, p.713-721, 2009.
CORN, J. L.; CUMBEE, J. C.; CHANDLER, B. A.; STALLKNECHT, D. E.; FISHER, J. R. Implications of feral swine expansion: Expansion of feral swine in the United States and potential implications for domestic swine. In: Feral swine subcommittee on brucellosis and pseudorabies report. Southeastern Cooperative Wildlife Disease Study, United States Animal Health Association, St. Joseph, Missouri, p.5-7, 2005.

FAO. The state of the world fisheries and aquaculture. Rome: Food and Agriculture Organization of the United Nations, 2012. Disponível: <http://www.fao.org/3/ai2727e.pdf>. Acesso $3 \mathrm{fev}$. 2017.

GARIN-BASTUJI, B.; HARS, J.; CALVEZ, D.; THIEBAUD, M.; ARTOIS, M. Brucellosis in domestic pigs and wild boar caused by brucella suis biovar 2 in france [in french]. Epidémiologie \& Santé animale, v.38, p.1-5, 2000.

IBAMA. O javali asselvajado. Norma e medidas de controle. Cartilha técnica IBAMA, p.1-8, 2016. Disponível: <http://www. ibama.gov.br/phocadownload/biodiversidade/javali/ibamacartilhajavali_asselvajado.pdf>. Acesso 06 fev. 2017.

MAPSTON, M. E. Feral Hogs in Texas. Texas Cooperative Extension, p.1-27, 2012.

MIELE, M. \& MACHADO, J. S. Levantamento sistemático da produção e abate de suínos -LSPS Metodologia AbipecsEmbrapa de previsão e acompanhamento da suinocultura brasileira. V Seminário Internacional de Aves e Suínos, 2005. Disponível: <https://www.agencia.cnptia.embrapa.br/recursos/ publicacao_estatistica.pdf>. Acesso 21 jun. 2017.

OIE. Porcine Brucellosis. Version adopted by the World Assembly of Delegates of the OIE em Mayo, 2009. Capítulo 2.8.5. Manual Terrestre de la OIE, p.1-8, 2012. Disponível: <https://web.oie.int/ eng/normes/MMANUAL/2008/pdf/2.08.05_PORCINE_BRUC. pd:>. Acesso 30 mai. 2017.

PEDROSA, F.; SALERNOB, R.; PADILHAC, F.V.B.; GALETTI, M. Current distribution of invasive feral pigs in Brazil: economic impacts and ecological uncertainty. Natureza \& Conservação, v.13, p.84-87, 2015.

RACHED, R. Z. Caracterização de pequenas criações de suínos no Estado de São Paulo. Dissertação (Mestrado em Sanidade, Segurança Alimentar e Ambiental no Agronegócio) - Instituto Biológico, São Paulo, 2009.

ROCHA, L. O.; OLIVEIRA, R. M.; HELLMEISTER FILHO, P.; GOMES N. A.; CARNEIRO, M. F.; SILVA, O. M.; FERNANDES, L. C. Panorama da criação de aves e suínos caipiras em regiões periurbanas no município de Senador Canedo (GO), Brasil.

CIAIQ - Investigação Qualitativa em Ciências Sociais, v.3, n.1, p.629-638, 2016. 
SALVADOR, C. H. \& FERNANDEZ, F. A. S. Using the Eurasian wild boar phenotype as a basis to document a new processo of invasion by Sus Scrofa I. in a Neotropical biodiversity. Wildlife Biology in Practice, v.10, n.3, p.22-29, 2014.

SAMPAIO, I. B. M. Estatística Aplicada à Experimentação Animal. 3. ed., Belo Horizonte: Fepmvz, 264p., 2007.

SEWARD, N. W. K. C.; VERCAUTEREN, G. W.; WITMER, R. M. Feral swine impacts on agriculture and the environment. Sheep \& Goat Research Journal, v.19, p.34-40, 2004.

SILVA FILHA, O. L. Experiências brasileiras na criação de suínos locais. Revista Computadorizada de Producción Porcina, La Habana, v.15, n.1, p.41-53, 2008

STOFFREGEN, W. C.; OLSEN, S. C.; JACK WHEELER, C.; BRICKER, B. J.; PALMER, M. V.; JENSEN, A. E.; HALLING, S. M.; ALT, D. P. Diagnostic characterization of a feral swine herd enzootically infected with Brucella. Journal of Veterinary Diagnostic Investigation, v.19, n.3, p.227-237, 2007.
TRIVINÕS, N. S. A. Introdução à pesquisa em ciências sociais A pesquisa qualitativa em educação. $1^{\mathrm{a}}$ ed. Atlas S.A, São Paulo, p.1-175, 1995.

WITMER, G. W.; SANDERS, R. B.; TAFT, A. C. Feral swineare they a disease threat to livestock in the United States? Proceedings of the Wildlife Damage Management Conference, v.10, p.316-325, 2003.

WU, N.; ABRIL, C.; THOMANN, A.; GROSCLAUDE, E.; DOHERR, M. G.; BOUJON, P.; RYSER DEGIORGIS, M. P. Risk factors for contacts between wild boar and outdoor pigs in Switzerland and investigations on potential Brucella suis spillover. BMC Veterinary Research, v.8, p.1-12, 2012.

WYCKOFF, A.; CHRISTY., HENKE, S. E., CAMPBELL, T. A., HEWITT, D. G; VERCAUTEREN, K. C. Feral swine contact with domestic swine: a serologic survey and assessment of potential for disease transmission. Journal of Wildlife Diseases, v.45, n.2, p.422-429, 2009. 